\title{
Canine autoimmune hemolytic anemia: management challenges
}

This article was published in the following Dove Press journal:

Veterinary Medicine: Research and Reports

26 July 2016

Number of times this article has been viewed

\author{
James W Swann' \\ Barbara J Skelly² \\ 'Queen Mother Hospital for Animals, \\ The Royal Veterinary College, \\ Hatfield, Hertfordshire, ${ }^{2}$ Department \\ of Veterinary Medicine, University of \\ Cambridge, Cambridge, UK
}

Correspondence: Barbara J Skelly Department of Veterinary Medicine, University of Cambridge, Madingley Road, Cambridge CB3 OES, UK

Tel +44 1223337649

Email bjs $1000 @$ cam.ac.uk
Abstract: Immune-mediated hemolytic anemia is one of the most common manifestations of canine immune-mediated disease, yet treatment regimens remain nonstandardized and, in some cases, controversial. The main reason for this, as for most diseases in veterinary medicine, is the lack of large-scale placebo-controlled trials so that the efficacy of one treatment over another can be established. Most of the evidence used for treatment comes from retrospective studies and from personal preference and experience, and because of this, treatment regimens tend to vary among institutions and individual clinicians. Management of immune-mediated hemolytic anemia includes immunosuppression, thromboprophylaxis, and supportive care measures to help prevent and treat concurrent conditions.

Keywords: IMHA, canine immune-mediated disease, management regimens

\section{Introduction}

Immune-mediated hemolytic anemia (IMHA) is considered to be the most common autoimmune disease in $\operatorname{dog} s^{1}$ and is encountered in first opinion and specialist practices in North America and Europe. Clinical features of the disease are the result of a spontaneous autoimmune response directed against normal glycoprotein molecules on the surface of the erythrocyte. ${ }^{2}$ Production of autoreactive antibodies during this response results in destruction of erythrocytes, either by complement-mediated lysis (so-called intravascular hemolysis) or due to phagocytosis by cells of the monocyte-phagocyte system in the liver and spleen (extravascular hemolysis). These processes result in anemia and, in some cases, prehepatic icterus due to accumulation of unconjugated bilirubin.

Following diagnosis, many dogs with IMHA receive blood products that are intended to achieve cardiovascular stability by improving the delivery of oxygen to peripheral tissues. A number of clinical parameters, grouped together as the Anemic Dog Clinical Assessment Score, have been evaluated as guides for administration of transfusions ${ }^{3 ;}$ however, there is currently no consensus regarding the optimal trigger for this procedure in dogs. The availability of blood products varies according to geographical location and type of veterinary practice, with some institutions maintaining colonies of donor animals and others relying on client-owned dogs or on charitable blood donation services for their supply. ${ }^{4}$

Glucocorticoid products are commonly used for treatment of IMHA in dogs; in a recent systematic review of studies produced at tertiary referral institutions, we found that these drugs had been administered to all of the dogs included in the review. ${ }^{5}$ 
Several other immunosuppressive drugs also have been used to treat the disease, including azathioprine, ${ }^{6,7}$ leflunomide, ${ }^{8}$ ciclosporin, ${ }^{9,10}$ and mycophenolate mofetil. ${ }^{11,12}$ There is currently no consensus among veterinarians regarding the optimal immunosuppressive regimen that should be used after a dog has been diagnosed with IMHA, and there has been considerable variation in the choice, dosage, duration, and rate of reduction of drugs used in studies published in the past 20 years. $^{5}$

IMHA is considered to have a poor prognosis in dogs, with mortality rates of $50 \%-70 \%$ reported in older studies, ${ }^{6,13}$ and rates of $\sim 30 \%-40 \%$ in more recent studies, ${ }^{14}$ presumably reflecting improvements in awareness of disease, speed of diagnosis, and availability of supportive care and blood products. A number of previous studies have investigated the associations between survival and the biochemical, hematologic, or clinical parameters that can be measured at presentation to determine whether these might have prognostic value. Review of the studies that assessed prognostic factors using a multivariable statistical model revealed that serum bilirubin and urea concentrations had each been significantly associated with survival in more than one previous study, ${ }^{15}$ suggesting that these variables might be helpful in guiding clinical decisions in future.

\section{Predicting disease outcome using scoring systems}

Because clinical presentation and response to treatment are variable in dogs with IMHA, a number of scoring systems have been developed to estimate the severity of disease and prognosis for dogs when they are diagnosed. These scores have been generated by investigating associations between individual clinicopathological variables and outcome, measured as survival time after diagnosis or percentage mortality at a defined time point. Summaries of two different prognostic scores are presented in Table 1. In a recent study, Goggs et $\mathrm{al}^{14}$ found that a combination of the American Society of Anesthesiologists' clinical grade and serum concentrations of bilirubin and urea or creatinine predicted mortality with greater accuracy than either of the scores described by Whelan et $\mathrm{al}^{16}$ or Ishihara et $\mathrm{al}^{17}$ in a sample of 276 dogs in the British Isles, but the authors unfortunately did not present their own model in the same form of a user-friendly score. An additional study revealed that the score developed in Japan did not predict survival in dogs with IMHA in Australia, ${ }^{18}$ highlighting the importance of using prognostic tools in a population for which they have been validated.
Table I Summary of two different prognostic scores developed for use in dogs with immune-mediated hemolytic anemia

\begin{tabular}{llll}
\hline Score & Parameter & Definition & Score \\
\hline CHAOS & Age & $\geq 7$ years & 2 \\
(Whelan et al) & \multicolumn{1}{l|}{ Rectal temperature } & $\geq 38.9^{\circ} \mathrm{C}$ & $\mathrm{I}$ \\
& Persistent agglutination after & Positive & $\mathrm{I}$ \\
& dilution in saline & & \\
& Serum albumin concentration & $<30 \mathrm{~g} / \mathrm{L}$ & $\mathrm{I}$ \\
& Serum bilirubin concentration & $\geq 85.5 \mu \mathrm{mol} / \mathrm{L}$ & 2 \\
& Total possible score & & 7 \\
Ishihara et al ${ }^{17}$ & Sex & Male & $\mathrm{I}$ \\
& Season & Warm & $\mathrm{I}$ \\
& Packed cell volume & $<20 \%$ & $\mathrm{I}$ \\
& Platelet count & $<200 \times 10^{3} / \mu \mathrm{L}$ & $\mathrm{I}$ \\
& Serum total protein & $<6 \mathrm{~g} / \mathrm{dL}$ & $\mathrm{I}$ \\
& concentration & & \\
& Total possible score & & 5 \\
\hline
\end{tabular}

Abbreviation: $\mathrm{CHAOS}$, canine haemolytic anaemia objective score.

Development of "intravascular hemolysis", a term used inconsistently to describe some combination of hemoglobinuria, hemolysed plasma, and presence of persistent agglutination of red blood cells, has traditionally been considered an indicator of a poor prognosis in dogs with IMHA. However, this perception is not supported by the majority of clinical studies of factors associated with survival: only two studies indicated using univariate analyses that autoagglutination was associated with decreased survival. One of these studies subsequently showed no difference between cases that had or did not have undefined "intravascular hemolysis", ${ }^{19}$ while the other demonstrated that agglutination was associated with survival to discharge but not to 1 year after diagnosis. ${ }^{20}$ In contrast, serum total bilirubin concentration, which is an indicator of the severity of either intravascular or extravascular hemolysis, has been associated consistently with survival in several previous studies that utilized either univariate or multivariate analyses, albeit with considerable variation in the apparent size of the effect. ${ }^{10,13-15,19,21-24}$ Consequently, we believe that this variable is likely to be the most useful for the clinician in guiding therapy and estimating prognosis, particularly because it is easily measured in the majority of primary care and specialist practices.

\section{Complications of conventional treatment The use of glucocorticoids and their side effects}

Corticosteroids, mainly the glucocorticoid - prednisolone, have been the mainstay of treatment for many years. No 
protocols are described that do not include corticosteroids, probably because many would consider it unethical to conduct a treatment trial that withholds this class of drugs. ${ }^{25}$ When other drugs are assessed for their usefulness in IMHA, they are given in conjunction with corticosteroids and compared to steroids alone. There have been no known multiple-patient published trials that have shown that any other immunosuppressive drug can be used alone in the management of IMHA, although anecdotal reports have suggested that this may be possible and ciclosporin has been used for this purpose by these authors in circumstances when owners have refused to use steroid therapy due to the side effects encountered.

Inflammatory responses are regulated by creating a balance between signals that stimulate and those that suppress. Endogenous glucocorticoids have a physiological role in suppression/modulation of inflammatory responses. Chronic autoimmune and inflammatory diseases develop when the stimuli to perpetuate the immune response outweigh the ability of endogenous glucocorticoids to suppress the response. This results in the hyperactivation of the immune system characteristic of these diseases. Treatment with synthetic glucocorticoids is used to control immune-mediated disease, taking advantage of the fact that endogenous glucocorticoids regulate immune responses.

Although steroids are undeniably effective at treating IMHA, they do so with a number of potentially severe side effects that have an impact on an owner's willingness to continue with treatment. Steroids cause polydipsia and polyuria through their interference with antidiuretic hormone function, polyphagia, panting, restlessness, muscle weakness and wasting, thromboembolic disease, and proteinuria. These signs of iatrogenic hyperadrenocorticism can be mild to severe and sometimes life threatening. In people, steroid use is much more restricted by side effects, and hypertension and osteoporosis are commonly seen. For this reason, it is rare that immune-mediated diseases in humans are managed with steroids alone, and other drugs, splenectomy, and monoclonal antibody treatments are used both for their efficacy and for their steroid-sparing effects. ${ }^{26}$

Steroids have the ability to worsen the clinical signs in an animal that already has signs of disease in another body system. An example of this would be the ability of steroid therapy to induce or worsen congestive heart failure in a dog with preexisting heart disease (eg, mitral valve endocardiosis or occult cardiomyopathy). In human medicine, the long-accepted recommendations are to avoid glucocorticoid administration in patients with heart failure due to the sodium and water retention they induce. More recently, it has been suggested that glucocorticoids may actually act synergistically with diuretics in some patients to improve diuresis and therefore clinical well-being. This area has not been explored in dogs and, as such, specific recommendations are difficult to justify. ${ }^{27}$

The drugs and their dosing regimens commonly used for the management of IMHA along with other management options are summarized in Table 2.

\section{Opportunistic infections}

Veterinarians managing dogs with IMHA may be concerned about the possibility of opportunistic infections when administering immunosuppressive drugs at high doses or in combinations, and a number of different infectious complications have been reported with the use of ciclosporin, alone or in combination with glucocorticoids. These include fungal infections,${ }^{30}$ bacterial urinary tract infections, ${ }^{34}$ disseminated nocardiosis, ${ }^{35-37}$ and papillomavirus-induced lesions, ${ }^{38}$ but there is little evidence available in dogs to indicate how often these complications arise.

In people, opportunistic infections do occur in patients receiving immunosuppressive therapy for a number of different autoimmune diseases and following transplantation. ${ }^{39,40}$ These appear to affect the respiratory tract most commonly, resulting in pneumonia with or without the involvement of the opportunistic organism Pneumocystis jirovecii. The latter organism could present a theoretical risk to dogs receiving immunosuppressive therapy but has been reported only in dogs with immunoglobulin deficiency, with or without B-cell hypoplasia. ${ }^{41-43}$ Immunocompromised people are also predisposed to development of active infections with Toxoplasma gondii, and a number of case reports indicate that similar complications could occur in dogs treated with immunosuppressive drugs due to reactivation of latent T. gondii and Neospora caninum infections. ${ }^{446}$

\section{Management of complex cases Failure to control the disease/relapses}

This section is illustrated by two case examples presented below.

\section{Case example I}

\section{Signalment}

Six-year-old male whippet; weight: $16 \mathrm{~kg}$.

\section{History}

This dog had a history of immune-mediated thrombocytopenia that had been previously treated with prednisolone 
Table 2 Management options for IMHA

\begin{tabular}{|c|c|c|c|c|}
\hline $\begin{array}{l}\text { Drug or } \\
\text { management } \\
\text { method }\end{array}$ & Dose & Mechanism of action & Adverse effects & $\begin{array}{l}\text { Cost and practicalities } \\
\text { of use }\end{array}$ \\
\hline \multicolumn{5}{|l|}{ Steroids } \\
\hline Glucocorticoid & $\begin{array}{l}\text { Prednisolone: } 2 \mathrm{mg} / \mathrm{kg} / \mathrm{d} \\
\text { reducing to I mg/kg/d after } \\
2-4 \text { weeks;dexamethasone: } \\
0.2-0.3 \mathrm{mg} / \mathrm{kg} / \mathrm{d} \text { until oral } \\
\text { medication can be started }\end{array}$ & $\begin{array}{l}\text { Alters gene } \\
\text { transcription;downregulates } \\
\text { Fc receptor expression, } \\
\text { decreases antigen processing, } \\
\text { and suppresses T-cell function }\end{array}$ & $\begin{array}{l}\text { PU/PD, polyphagia, panting, } \\
\text { muscle wasting, weight gain, } \\
\text { opportunistic infections, } \\
\text { Gl ulceration, diabetes mellitus, } \\
\text { osteoporosis, thromboembolic } \\
\text { disease }\end{array}$ & $\begin{array}{l}\text { Inexpensive; I mg, } \\
5 \mathrm{mg} \text {, and } 25 \mathrm{mg} \text { tablets } \\
\text { available; injectable } \\
\text { dexamethasone } \\
\text { convenient if vomiting } \\
\text { present }\end{array}$ \\
\hline Anabolic steroid & $\begin{array}{l}\text { Nandrolone: } \mathrm{I}-5 \mathrm{mg} / \mathrm{kg} \\
\text { intramuscularly/ } \\
\text { subcutaneously, maximum } \\
\text { dose } 40-50 \mathrm{mg} \text { per dog; } \\
\text { repeated every } 2 \mathrm{I} \text { days }\end{array}$ & $\begin{array}{l}\text { Thought to stimulate } \\
\text { erythropoiesis in nonregenerative } \\
\text { anemia; mechanism unproven }\end{array}$ & $\begin{array}{l}\text { Sodium, calcium, potassium, } \\
\text { chloride, phosphate retention; water } \\
\text { retention; hepatotoxicity, behavioral } \\
\text { changes, reproductive abnormalities } \\
\text { (oligospermia, estrus suppression) }\end{array}$ & $\begin{array}{l}\text { Parenteral form only; } \\
\text { easy to administer; lack of } \\
\text { information about efficacy } \\
\text { means anabolic steroids } \\
\text { are rarely recommended }\end{array}$ \\
\hline \multicolumn{5}{|c|}{ Steroid-sparing drugs } \\
\hline Azathioprine & $\begin{array}{l}2 \mathrm{mg} / \mathrm{kg} / \mathrm{d} \text { po for no more } \\
\text { than } \mathrm{l} 4 \text { days; then decrease } \\
\text { to } 1 \mathrm{mg} / \mathrm{kg} \text { po every day or } \\
2 \mathrm{mg} / \mathrm{kg} \text { EOD depending on } \\
\text { ease of dosing; or, } 50 \mathrm{mg} / \mathrm{m}^{2} \\
\text { every other day }\end{array}$ & Thiopurine analog & $\begin{array}{l}\text { Hepatotoxicity, }{ }^{28} \text { bone marrow } \\
\text { suppression, pancreatitis; most side } \\
\text { effects follow use of } 2 \mathrm{mg} / \mathrm{kg} \text { daily } \\
\text { dosing for }>2 \text { weeks though side } \\
\text { effects can occur in dogs that have } \\
\text { pre-existing disease in these organs } \\
\text { or disease susceptibility }\end{array}$ & $\begin{array}{l}\text { Inexpensive ( } 25 \mathrm{mg} \\
\text { and } 50 \mathrm{mg} \text { tablets); } \\
\text { other doses have to be } \\
\text { reformulated; do not split } \\
\text { tablets; not licensed for } \\
\text { use in dogs in the UK }\end{array}$ \\
\hline Ciclosporin & $2.5-5 \mathrm{mg} / \mathrm{kg}, \mathrm{po}, \mathrm{q} / 2 \mathrm{~h}$ & Calcineurin inhibitor & $\begin{array}{l}\text { Gl signs (vomiting, diarrhea, } \\
\text { anorexia), gingival hyperplasia, }{ }^{29} \\
\text { opportunistic infections; }{ }^{30} \\
\text { ciclosporin is not cytotoxic and is } \\
\text { not myelosuppressive as it is } \\
\text { specific for lymphocytes }\end{array}$ & $\begin{array}{l}\text { Expensive; capsules } \\
\text { available in } 10 \mathrm{mg}, 25 \mathrm{mg} \text {, } \\
50 \mathrm{mg} \text {, and } 100 \mathrm{mg} \\
\text { formulations; liquid } \\
\text { formulation available; not } \\
\text { licensed for use for this } \\
\text { condition but licensed for } \\
\text { use in dogs in the UK }\end{array}$ \\
\hline $\begin{array}{l}\text { Mycophenolate } \\
\text { mofetil }\end{array}$ & $10 \mathrm{mg} / \mathrm{kg}$, po, q $12 \mathrm{~h}$ & Purine synthesis inhibitor & $\begin{array}{l}\text { Gl upset, lethargy, hepatotoxicity, } \\
\text { bone marrow suppression }\end{array}$ & $\begin{array}{l}250 \mathrm{mg} \text { and } 500 \mathrm{mg} \\
\text { capsules; available as } \\
\text { Cellcept and also in } \\
\text { generic form; not licensed } \\
\text { for use in dogs in the UK }\end{array}$ \\
\hline Leflunomide & $\mathrm{l}-4 \mathrm{mg} / \mathrm{kg}$, po, q24h & Pyrimidine synthesis inhibitor & $\begin{array}{l}\text { Gl upset, bone marrow } \\
\text { suppression, hepatotoxicity }\end{array}$ & $\begin{array}{l}10 \text { and } 20 \mathrm{mg} \text { tablets } \\
\text { Not licensed for use in } \\
\text { dogs in the UK }\end{array}$ \\
\hline Lithium carbonate & I0-1 I mg/kg orally, bid & Stimulates erythropoiesis & $\begin{array}{l}\text { Diarrhea, hypersalivation, } \\
\text { seizures, increased liver } \\
\text { enzymes, PU/PD }\end{array}$ & $\begin{array}{l}\text { Little information about } \\
\text { use in dogs; serum levels } \\
\text { should be measured; } 31,32 \\
\text { not licensed for use in } \\
\text { dogs in the UK }\end{array}$ \\
\hline
\end{tabular}

Rescue therapies

$\begin{array}{ll}\mathrm{hIVlg} & 0.5-1.0 \mathrm{~g} / \mathrm{kg} \text {, iv, over } \\ 6-12 \text { hours } & \text { Fc receptor blockade }\end{array}$

Plasmapheresis N/A

Splenectomy N/A

\section{Microporous membrane separation of plasma from other blood components before immunoglobulins are filtered from plasma to limit immune response Underlying etiology of IMHA involves antibody-mediated red cell destruction by the spleen; removal of spleen removes site of destruction}

Thromboembolic disease, volume overload, anaphylaxis

Hypocalcemia due to anticoagulants in circuit

$\begin{array}{ll}\text { Increased susceptibility to infectious } & \text { One-off surgical and } \\ \text { agents, risks associated with } & \text { aftercare costs; patient } \\ \text { anesthesia and surgery in a dog } & \text { needs to be stabilized } \\ \text { with IMHA (thromboembolic } & \text { for anesthesia - usually } \\ \text { disease etc) } & \text { requires transfusion }\end{array}$

Expensive; do not repeat infusion; not licensed for use in dogs in the UK

Requires specialist equipment/expertise; limited experience in $\operatorname{dogs}^{33}$
N/A, not applicable; po, per os; Abbreviations: bid, twice daily; GI, gastrointestinal; hIVIg, human intravenous immunoglobulin; IMHA, immune-
q $12 \mathrm{~h}$, every 12 hours; q24h, every 24 hours; EOD, every other day; PU/PD, polyuria/polydipsia; iv, intravenous. 
and azathioprine. The treatment had been tapered off and had stopped completely 9 months prior to the dog becoming unwell again.

The dog had a 3-week history of lethargy and inappetence. He was identified as having a regenerative anemia at his primary practice (packed cell volume [PCV]: 25\%) and was put on treatment using prednisolone at a dose rate of $1 \mathrm{mg} / \mathrm{kg} / \mathrm{d}$ initially, which was increased to $2 \mathrm{mg} / \mathrm{kg} / \mathrm{d} 12$ days before referral because the initial response to treatment was poor. Although the response to the dose increase was positive at first (PCV increased to $42 \%$ ), the dog again deteriorated, the PCV dropped, and he was referred to the Queen's Veterinary School Hospital.

This was a client-owned animal. Owner consent was obtained plus consent for the use of drugs not licensed in this species. This was in no way an experimental procedure but was an attempt to rescue a clinical case from dramatic deterioration using licensed and non-licensed drugs that are reported to be useful in these cases.

\section{Clinical examination}

The dog was lethargic but reasonably bright. He had normal temperature and respiratory rate, and a heart rate of $80 \mathrm{bpm}$. His mucous membranes were pale and icteric. His temperature was $38.9^{\circ} \mathrm{C}$.

\section{Investigation}

Blood work showed moderate anemia (PCV: 25\%), with evidence of regeneration and spherocytosis. There was mild thrombocytopenia (platelet count: $109 \times 109 / \mathrm{L}$; range: 175-500×109/L). Total protein was $74 \mathrm{~g} / \mathrm{L}(60-80 \mathrm{~g} / \mathrm{L})$. Bilirubin was mildly increased $(56 \mathrm{mmol} / \mathrm{L}$; range: 0-12 mmol/L). Coombs test was negative. In-saline agglutination test was positive.

Survey radiographs of thorax and abdomen revealed no abnormalities, and abdominal ultrasonography was unremarkable.

\section{Diagnosis}

The history, clinical examination, and laboratory findings were compatible with a diagnosis of immune-mediated hemolytic anemia (IMHA).

\section{Management}

The dog continued to be on prednisolone $(2 \mathrm{mg} / \mathrm{kg} / \mathrm{d})$ and azathioprine was added $(2 \mathrm{mg} / \mathrm{kg} / \mathrm{d})$. Over the next 24 hours, the dog's condition deteriorated significantly and he became pyrexic, lethargic, pale, and tachypneic. His PCV was found to have dropped to $11 \%$. He was given one unit of packed red cells, and his posttransfusion PCV was $25 \%$. He also received $10 \mathrm{~g}$ of human intravenous immunoglobulin (hIVIg) as a constant rate infusion over 4 hours.

The dog was sent home with PCV stable at $20 \%$ and receiving prednisolone ( $2 \mathrm{mg} / \mathrm{kg} / \mathrm{d})$, azathioprine (2 $\mathrm{mg} / \mathrm{kg} / \mathrm{d}$ ), ciclosporin (3 $\mathrm{mg} / \mathrm{kg}$, bid), and clopidogrel $(56.25 \mathrm{mg} / \mathrm{d})$.

The dog returned to the hospital for reassessment after 3 days, by which time his PCV was $25 \%$ with a strongly regenerative response. Ciclosporin caused persistent diarrhea in this dog and was tapered and discontinued over 2 weeks. After 2 weeks, the prednisolone dose was decreased to $1 \mathrm{mg} / \mathrm{kg} / \mathrm{d}$. A recheck after 1 month showed that the PCV had increased to $44 \%$, and the dog was doing well.

Medication was maintained at immunosuppressive levels for 3 months, then a tapering regimen began.

\section{Discussion}

This case shows that in dogs with a predisposition for immunemediated disease, different diseases can present either at the same time or, as in this case, serially in a dog's lifetime. When therapy with prednisolone was started to treat IMHA, it began at the fairly modest dose of $1 \mathrm{mg} / \mathrm{kg} / \mathrm{d}$. Although this was increased after 7 days, response was transient. The dog then deteriorated rapidly, having been relatively stable for a period of about 3 weeks. Treatment intensity was increased using azathioprine, but this drug is thought not to have rapid onset of action and probably did little to prevent the hemolytic crisis that the dog entered. hIVIg was chosen at this point because of its perceived rapid onset of action. This patient responded well both clinically and hematologically and was discharged from the hospital in a stable condition.

\section{Case example 2}

\section{Signalment}

Eight-year-old male, entire, Irish setter dog; weight $42 \mathrm{~kg}$.

\section{History}

This Irish setter had a history of reduced exercise tolerance, disorientation and collapse on exercise, and tachypnea. He was hypothyroid and had been receiving thyroid supplementation.

This was a client-owned animal. Owner consent was obtained.

\section{Clinical examination}

The dog was bright and appeared normal in attitude. He had a normal temperature; respiratory rate was $56 \mathrm{bpm}$ and heart 
rate was $150 \mathrm{bpm}$. His mucous membranes were pale, with a normal capillary refill time. His abdomen appeared to be pendulous, with suspected cranial abdominal organomegaly.

\section{Investigation}

Blood work showed marked anemia (PCV: 14\%), with no evidence of regeneration. There was marked leukocytosis along with neutrophilia $(31.56 \times 109 / \mathrm{L}$; range: $3-11.5 \times 109 /$ L). There was marked thrombocytosis (platelet count: $2,275 \times 109 / \mathrm{L}$; range: $175-500 \times 109 / \mathrm{L})$. Total protein was $70 \mathrm{~g} / \mathrm{L}$ (range: $60-80 \mathrm{~g} / \mathrm{L}$ ). No spherocytosis or in-saline agglutination was seen. Bilirubin was normal (3.1 mmol/L; range: 0-12 $\mathrm{mmol} / \mathrm{L})$. Coombs test was negative.

Survey radiographs of thorax and abdomen revealed no abnormalities, and abdominal ultrasonography was unremarkable.

Bone marrow aspiration and core biopsy were suggestive of pure red cell aplasia (PRCA) as there were few to no red cell precursors identified. The majority of cells were myeloid, with evidence of maturation to the segmented neutrophil stage.

\section{Diagnosis}

The history, clinical examination, and laboratory findings were compatible with a diagnosis of PRCA of presumed immune-mediated etiology in the absence of any other pathological changes.

\section{Management}

The dog was treated with prednisolone $(2 \mathrm{mg} / \mathrm{kg} / \mathrm{d})$ and ciclosporin $(2.5 \mathrm{mg} / \mathrm{kg}$, bid). He remained nonregenerative and was transfusion dependent for the following 3 weeks. At this point, lithium carbonate $(10 \mathrm{mg} / \mathrm{kg}$, bid) was added to his dosage regimen. Three weeks later, when again the dog required transfusion, ciclosporin was withdrawn and mycophenolate mofetil was added $(10 \mathrm{mg} / \mathrm{kg}$, bid $)$

\section{Outcome}

No improvement was seen in the red cell parameters, and no indication of regeneration was seen. In addition, the dog developed a skin lesion on the bridge of his nose, which cytologically was found to contain fungal hyphae. Lithium carbonate dose was decreased to $10 \mathrm{mg} / \mathrm{kg} / \mathrm{d}$ following some adverse effects. The dog continued to do badly, however, made no response to mycophenolate, and was euthanized due to both absence of response to treatment and the development of hemorrhagic gastroenteric signs.

\section{Discussion}

This dog illustrates some of the frustrations encountered with bone marrow-centered disease. There were few indi- cations of the etiology of the anemia in this Irish setter and the disease was presumed to be immune mediated in the absence of any other drug-related, toxic, neoplastic, or inflammatory disease. The dog was supported with transfusions and was immunosuppressed. When there was no response, other additional therapies were used, including lithium carbonate and then mycophenolate mofetil. Lithium has a small body of literature to support its use and was not helpful in this case (Table 1). Mycophenolate has been reported in small numbers of canine IMHA cases and was reported to provoke few side effects in canine patients when used in conjunction with steroids. It may prove useful as an alternative agent in the management of this disease. ${ }^{11}$ Unfortunately, it also was not helpful in this case, and the dog was euthanized.

Survival curves constructed from data obtained from dogs with IMHA show curves with similar slopes reflecting the fact that most deaths occur in the first 2 weeks after diagnosis. ${ }^{13,24,47}$ Problems arise when immunosuppressive regimens are instituted and there is either no control of the hemolytic process or no regenerative state is achieved. In these circumstances, clinicians often look to increase the breadth of the immunosuppression by adding other agents. Most dogs achieve initial control using prednisolone \pm another agent, usually azathioprine or ciclosporin. When there is a less-than-optimal response to treatment, other agents are added, including azathioprine and ciclosporin, to increase to two immunosuppressive agents or three depending on whether the dog was on mono or dual therapy to begin with. If this does not alter the disease process, there are a number of options for clinicians, none of which is the accepted and evidence-proven route.

Several studies have looked at the role of human intravenous immunoglobulin (hIVIg) for this purpose. As far back as 1997, Kellerman and Bruyette suggested that hIVIg would be a good option for dogs that did not respond to prednisolone therapy within 7 days. ${ }^{48}$ This was reiterated by a later study, ${ }^{49}$ but better long-term survival was not proven. ${ }^{50,51}$ In one published prospective study, again hIVIg did not alter response to treatment or survival, ${ }^{23}$ although the survival data compared favorably to those in other studies (24/28 survived to 2 weeks, $86 \%$ ). The question that has not been answered by these studies is whether hIVIg is able to alter prognosis and survival in a dog that would not otherwise have responded to standard medication, ie, one that would be expected to have a poor prognosis based on our current understanding of prognostic markers. For this to be answered, clinicians would have to have at their disposal a robust prognostic scoring system that could reliably pick out dogs that may benefit from more intensive drug regimens. 
In the literature on human medicine, a strong case is made for the role of splenectomy in IMHA patients, with survival rates encouragingly high. ${ }^{52}$ The idea that splenectomy may be helpful is decades old in veterinary medicine too, with reports dating back to 1985 reporting $100 \%$ survival in three dogs with IMHA. ${ }^{53}$ More recently, a retrospective study evaluated ten dogs that were splenectomized as part of their treatment for IMHA. ${ }^{54}$ This study showed $90 \%$ survival at 30 days, with packed cell volumes (PCVs) rising significantly 3 days after the procedure and reduced requirement for transfusion. These studies appear to suggest that IMHA could be managed successfully by splenectomy and that this technique warrants further investigation through a larger-scale prospective study.

Disease relapse also poses problems for IMHA cases. Recommended treatment times vary anecdotally between 3 months and 6 months and are rarely standardized, though some authors ${ }^{55}$ have found it helpful to use standard protocols within their institution, with the result that retrospective studies become more meaningful and data collection is easier. The treatment regimen described at Utrecht, the Netherlands, follows a 69-day gradually tapering course. Relapses prompt a return to the beginning of the regimen. Too rapid tapering has been associated with increased incidence of relapse, but strong evidence for this is lacking in the literature.

\section{Nonregenerative immune-mediated anemia}

Classically, IMHA is diagnosed when an animal has a regenerative anemia associated with autoagglutination, Coombs test positivity, and spherocytosis in the absence of any recognizable underlying disease pathology. The regenerative response does not happen immediately, however, and 3-5 days are required before an adequate reticulocyte response is recognized after acute hemolysis. If there is no appropriate reticulocyte response after 5 days, then it is still possible that immune-mediated disease is the cause, and animals may have either pure red cell aplasia (PRCA) or nonregenerative IMHA. ${ }^{56}$ PRCA is diagnosed when erythroid aplasia results from presumed immune-mediated destruction of precursor cells within the bone marrow. ${ }^{56-58}$ Nonregenerative IMHA appears to be a related disorder in that immune-mediated red cell destruction takes place within the marrow, and maturation arrest of the erythroid lineage at different stages of maturation can be recognized. In addition, some forms of nonregenerative IMHA are associated with bone marrow erythroid hyperplasia ${ }^{59}$ and other pathological changes such as dysmyelopoiesis, myelonecrosis, myelofibrosis, and hemophagocytic syndrome. Dogs that have similar hematological changes peripherally can therefore have very different bone marrow profiles varying from PRCA to erythroid hyperplasia.

Although the names PRCA and nonregenerative IMHA have been given to these conditions based on the cytological evaluation of the bone marrow, from a purely clinical perspective, it would appear that PRCA is just one end of a continuum of immune-mediated disease, which begins as destruction of early precursors and ends with destruction of mature circulating cells. These diseases all have the same feature of immune-mediated cell lysis and should all respond to immunosuppression, albeit to different degrees. Giving a specific disease name, such as PRCA, suggests it is a separate disease entity and somehow is unrelated to peripheral IMHA. We would argue that these diseases are closely related and are only separated by the stage of maturation of the cell type that is the specific target for autoantibody production. As such, management regimens are similar in all cases.

The prognosis for dogs with PRCA is reported to be fair within the available literature, with survival rates of $72 \%-79 \%{ }^{56,59}$ However, numbers are low and the authors' perception is that these diseases are more difficult to manage. In one study, ${ }^{59}$ dogs with nonregenerative IMHA and erythroid hyperplasia were shown to have statistically significant lower 60-day survival rate (56\%) when compared with dogs showing maturation arrest or PRCA. Again, low numbers make this information open to interpretation. Many clinicians would choose a more aggressive multidrug form of therapy from the outset for these cases or would ramp up therapy after treatment with steroid alone fails to resolve the disease within a reasonable timeframe (10-14 days). The evidence for such choices is lacking, however, and because much of the literature is $\geq 8$ years old, it does not include information about newer drug choices such as mycophenolate or even ciclosporin.

\section{Thromboembolic disease}

Formation of thrombi is one of the major complications suffered by dogs with IMHA, ${ }^{47,60}$ and the pathophysiology of this process has been reviewed elsewhere. ${ }^{61}$ Pulmonary thromboembolism (PTE) is reported most commonly, but vessels in other locations, including the brain, spleen, portal vasculature, and kidneys, may be affected. ${ }^{22,24,62}$ One of the major challenges involved in managing PTE in dogs with IMHA is the difficulty in diagnosing this complication ante mortem. Formation of a thrombus does not result in reliable changes in the radiographic appearance of the lungs, ${ }^{63}$ nor does it consistently cause hypoxemia in all cases. ${ }^{64} \mathrm{~A}$ recent 
study indicated that computed tomography with pulmonary angiography, which is considered the gold standard imaging modality for diagnosis of PTE in people, might produce greater diagnostic accuracy, ${ }^{65}$ but this form of imaging is expensive and not readily available in clinical practice. As a result, PTE is often suspected if there are consistent clinical and laboratory findings, such as acutely increased respiratory rate and effort, hypoxemia, and increased alveolar-to-arterial oxygen gradient, ${ }^{66}$ but it may be difficult to establish whether these changes could have a different etiology, such as secondary bacterial pneumonia, acute respiratory distress syndrome, or increased respiratory drive due to cerebral hypoxia.

There has been frequent speculation that development of thromboembolic disease is predictive of poor outcome in dogs with IMHA, ${ }^{22,62}$ but definitive proof of this hypothesis is lacking, partly due to the difficulty in confirming the existence of the problem in live animals. Paradoxically, greater maximal amplitude values obtained by thromboelastography in dogs with IMHA were associated with improved survival, ${ }^{67,68}$ probably because development of consumptive coagulopathy is associated with poor prognosis.

Due to its importance as a possible cause of additional morbidity and mortality, there has been extensive discussion of the use of anticoagulant therapy, either for symptomatic animals or as prophylaxis for those recently diagnosed with the disease. ${ }^{61}$ These discussions are somewhat hampered by an incomplete understanding of the processes that result in a systemic hypercoagulable state and increased risk of clinically detectable thromboembolic disease, as well as by the lack of concrete evidence to support an association between development of thromboembolic disease and increased risk of death.

Among the drugs evaluated in clinical practice, some inhibit platelet activation (aspirin and clopidogrel) and some limit the activity of coagulation factors (unfractionated and low-molecular-weight heparin). As with immunosuppressive treatment, there is no consensus among veterinarians as to the preferred form of anticoagulant therapy, ${ }^{5}$ and it is likely that requirements will differ widely between individual patients according to the severity of their disease.

A large retrospective study investigated the outcome associated with several different anticoagulant regimens that were administered to dogs with IMHA shortly after diagnosis and alongside a standardized immunosuppressive protocol that included prednisone and azathioprine. ${ }^{60}$ This study demonstrated that administration of aspirin at an "ultra-low" dose of $0.5 \mathrm{mg} / \mathrm{kg}$ twice daily resulted in improved survival, compared to dogs that received no anticoagulant drug, heparin alone, or a combination of aspirin and heparin. A smaller prospective and randomized study evaluated the use of clopidogrel alone, ultra-low-dose aspirin alone, or a combination of the two drugs, but this did not reveal any significant difference in survival between the three regimens. ${ }^{69}$ While apparently not supporting the use of clopidogrel in dogs with IMHA, this study is likely to have been underpowered, recruiting just six cases per group. There is suspicion that a proportion of dogs with IMHA will also have platelets that are relatively resistant to the action of aspirin, as has been reported in people. In this situation, it may be of benefit to consider the use of an alternative antiplatelet drug if platelet function testing becomes more affordable and accessible in veterinary practice in future.

Use of heparin for management of thrombi has several theoretical advantages because venous thromboembolic disease is classically associated with inappropriate activation of the coagulation cascade, rather than abnormal platelet activity. ${ }^{61}$ This class of drugs is also used widely in people who have similar diseases, including deep vein thrombosis and PTE related to recent surgery or cardiac disease. ${ }^{70}$ Both unfractionated and low-molecular-weight heparin have been administered to dogs with IMHA in an attempt to reduce the frequency and severity of thromboembolic disease, but the regimens and the studies used to evaluate their effects have varied widely. ${ }^{5}$

Helmond et $\mathrm{al}^{71}$ performed a randomized controlled trial to compare the effects of administering unfractionated heparin at a conventional and fixed dose from the point of diagnosis with those in dogs in whom the dose of heparin was adjusted on a daily basis according to the results of repeated factor X assays. The latter group of dogs had significantly improved survival and required a wider variety of different heparin doses to achieve the desired reduction in factor $\mathrm{X}$ concentration. This study highlights the importance of close monitoring of heparin therapy if it is to be instituted; previous reports in people also indicate that different individuals require different doses of unfractionated heparin, limiting its use outside of the hospital environment. ${ }^{72}$ While possibly representing a valuable addition to therapy in dogs in whom PTE or similar disease is suspected, some forms of heparin are expensive, and access to factor $\mathrm{X}$ assays is limited to a small number of veterinary institutions. Similar assays are available at many human hospitals, so monitoring may be feasible if a good working relationship exists with a local center.

\section{Bilirubin encephalopathy}

There have been two case reports of dogs suffering neurological signs that appeared to be related to increased serum bilirubin concentrations, ${ }^{73}$ one in a dog with primary IMHA. ${ }^{74}$ 
This phenomenon, properly termed bilirubin encephalopathy and occasionally kernicterus, has been described most commonly in human neonates and rarely in adults with deficient activity of the hepatic enzyme uridine diphosphate glucuronyl transferase, which is responsible for conjugation of bilirubin.

Bilirubin encephalopathy is suspected in people with excessive total serum bilirubin concentrations (usually $>500$ $\mathrm{mmol} / \mathrm{L}$ ) who begin to show neurological signs. In the dog with IMHA in which it was suspected, magnetic resonance imaging of the brain revealed increased intensity in T2-weighted images of the basal ganglia and other central nuclei, ${ }^{74}$ and post mortem examination of both adult dogs diagnosed with the disease showed yellow pigmentation of the thalamus.

In clinical practice, the majority of dogs do not develop hyperbilirubinemia that is so severe as to result in bilirubin encephalopathy, but we believe that this condition should be considered in icteric animals that develop neurological signs with no other apparent etiology.

\section{Distal renal tubular acidosis}

A case series published in 2009 described distal renal tubular acidosis in three dogs with IMHA. ${ }^{75}$ In all three cases, the diagnosis was based on the presence of metabolic acidosis with normal anion gap and inappropriately high urine anion gap and bicarbonate excretion.

The acidemia was treated in all three dogs with infusions of sodium bicarbonate, but all were ultimately euthanized. Immune-mediated disease is reported to be the most common cause of acquired distal renal tubular acidosis in people, ${ }^{76}$ particularly in association with systemic lupus erythematosus, rheumatoid arthritis, and Sjogren's syndrome, affecting up to one quarter of patients. ${ }^{77-79}$ It has been suggested that the phenomenon develops due to production of autoantibodies that interfere with the action of ion transporters in the distal tubule. ${ }^{80}$

It is not known how frequently distal renal tubular acidosis develops in dogs with IMHA or other autoimmune diseases, or whether it has any impact on the outcome in affected dogs. In people, acidosis is usually treated with potassium citrate rather than sodium bicarbonate, as this will treat both acidosis and hypokalemia, which are frequently observed concurrently. ${ }^{81}$

\section{Hemoglobin-related acute kidney injury}

Experience gained from treating human injuries during World War II suggested that excessive circulating concentrations of myoglobin and free hemoglobin could cause acute kidney injury, and the same syndrome was produced experimentally by injecting hemoglobin into dogs in $1947 .{ }^{82}$ More recent studies suggest that heme proteins cause damage to the kidneys in several different ways, including oxidant damage to cellular molecules and changes in blood flow due to sequestration of nitric oxide. ${ }^{83}$

It would appear that azotemic acute kidney injury is not common in dogs with IMHA as it has not been reported frequently in dogs with this disease, although increased serum concentrations of both urea and creatinine have been associated with decreased survival in affected dogs. ${ }^{7,10,14,50}$

Interestingly, a study of dogs at high risk of hemoglobin-induced nephropathy (including dogs with IMHA, dogs infected with Babesia canis rossi, and dogs that had been injected with large amounts of hemoglobin) reported serum creatinine concentrations within normal limits in all groups. ${ }^{84}$

Glomerular filtration rate was also measured in all individuals and was reported to be "normal", but it is not clear whether these values were standardized to breed and age group reference intervals.

In conclusion, while release of large amounts of free hemoglobin into the circulation could increase the risk of acute kidney injury, this phenomenon has not been reported frequently in the veterinary literature. Furthermore, in animal patients with greatly reduced blood oxygen-carrying capacity and systemic inflammation, it may be difficult to establish whether azotemia has developed due to the effect of heme moieties in the kidneys. ${ }^{85}$

\section{Association between vaccination and IMHA}

There have been anecdotal reports that recent vaccination could be associated with development of IMHA in dogs, and a study conducted in the US suggested that dogs with IMHA were much more likely to have been vaccinated in the month prior to onset of clinical signs than a group of control dogs presented for management of other diseases. ${ }^{19}$ The results of this study were not duplicated by another, larger investigation, which found no relationship between timing of vaccination and onset of clinical signs. ${ }^{22}$ While there does appear to be a consistent relationship between some vaccines and development of immune thrombocytopenic purpura in people, ${ }^{86}$ there are only sporadic reports of development of acute autoimmune hemolytic anemia after vaccination. ${ }^{87}$

A topic often raised by owners and veterinarians is whether continued vaccination induces relapse of IMHA, but, to our knowledge, there have been no published studies reporting the frequency of this phenomenon in dogs with IMHA. While there is no evidence to suggest that vaccination will cause relapses, it is possible for serum antibody titers against canine distemper virus, parainfluenza virus, and adenovirus 1 to be measured 
to guide the decision to vaccinate. Protective antibody titers against Leptospira organisms are unlikely to persist beyond 1 year, so we usually counsel owners and veterinarians that the decision to administer this vaccine should be based on a consideration of risks and benefits for the individual animal. For example, there may be little indication to vaccinate a dog that lives mostly indoors in an area with a low prevalence of Leptospira infections, whereas vaccination may well be indicated in working dogs or in dogs that are exposed to waterways. ${ }^{88}$

\section{Conclusion: future directions and comparative aspects}

IMHA throws up many challenges for the small animal physician, and it remains a disease that may respond unpredictably or poorly to medication and may still be fatal in a significant number of cases. Treatment of canine patients relies almost solely on immunosuppression, with splenectomy not universally used as a reasonable alternative. The situation is similar in human medicine wherein steroids remain in use as first-line agents with or without cyclophosphamide. ${ }^{89}$ In people, there has been an attempted movement away from immunosuppression toward the use of therapeutic monoclonal antibodies, though these remain rather nonspecific and therefore of mixed efficacy. ${ }^{89}$ In children particularly, treatments with agents such as rituximab, a monoclonal antibody against the cluster of differentiation (CD)-20 molecule which causes B-cell depletion, are used to avoid high doses of steroids or splenectomy, both of which cause significant and severe side effects. ${ }^{90}$ The search for more specific ways to treat autoimmune hemolytic anemia in people continues and relies on the need to define the origin of the stimulus to mount an immune response against red blood cells, so that the stimulus can be removed and the immune dysregulation corrected. However, this approach may still be some way in the future for human and veterinary patients.

\section{Disclosure}

The authors report no conflicts of interest in this work.

\section{References}

1. McCullough S. Immune-mediated hemolytic anemia: understanding the nemesis. Vet Clin North Am Small Anim Pract. 2003;33(6):1295-1315.

2. Balch A, Mackin A. Canine immune-mediated hemolytic anemia: pathophysiology, clinical signs, and diagnosis. Compend Contin Educ Vet. 2007;29(4):217-225.

3. Kisielewicz C, Self I, Bell R. Assessment of clinical and laboratory variables as a guide to packed red blood cell transfusion of euvolemic anemic dogs. J Vet Intern Med. 2014;28(2):576-582.

4. Kiesielewicz C, Self IA. Canine and feline blood transfusions: controversies and recent advances in administration practices. Vet Anaesth Analg. 2014;41(3):233-242.
5. Swann JW, Skelly BJ. Systematic review of evidence relating to the treatment of immune-mediated hemolytic anemia in dogs. J Vet Intern Med. 2013;27(1):1-9.

6. Mason N, Duval D, Shofer FS, Giger U. Cyclophosphamide exerts no beneficial effect over prednisone alone in the initial treatment of acute immune-mediated hemolytic anemia in dogs: a randomized controlled clinical trial. J Vet Intern Med. 2003;17(2):206-212.

7. Piek C, Junius G, Dekker A, Schrauwen E, Slappendel RJ, Teske E. Idiopathic immune-mediated hemolytic anemia: treatment outcome and prognostic factors in 149 dogs. J Vet Intern Med. 2008;22(5):366-373.

8. Gregory CR, Stewart A, Sturges B, et al. Leflunomide effectively treats naturally occurring immune-mediated and inflammatory diseases of dogs that are unresponsive to conventional therapy. Transplant Proc. 1998;30(8):4143-4148.

9. Husbands B, Polzin D, Armstrong P, Cohn L, Patterson N [homepage on the Internet]. Prednisone and cyclosporine vs. prednisone alone for treatment of canine immune-mediated hemolytic anemia (IMHA). In: ACVIM Proceedings 2004. Available from: http://www.vin.com/. Accessed April 20, 2016.

10. Swann JW, Skelly BJ. Evaluation of immunosuppressive regimens for immune-mediated hemolytic anemia: a retrospective study of $42 \mathrm{dogs}$. J Small Anim Pract. 2011;52(7):353-358.

11. Wang A, Smith JR, Creevy KE. Treatment of canine idiopathic immunemediated haemolytic anaemia with mycophenolate mofetil and glucocorticoids: 30 cases (2007 to 2011). J Small Anim Pract. 2013;54(8): 399-404.

12. West LD, Hart JR. Treatment of idiopathic immune-mediated hemolytic anemia with mycophenolate mofetil in five dogs. JVet Emerg Crit Care (San Antonio). 2014;24(2):226-231.

13. Klag A, Giger U, Shofer F. Idiopathic immune-mediated hemolytic anemia in dogs: 42 cases (1986-1990). JAm Vet Med Assoc. 1993;202(5): 783-788.

14. Goggs R, Dennis SG, Di Bella A, et al. Predicting outcome in dogs with primary immune-mediated hemolytic anemia: results of a multicenter case registry. J Vet Intern Med. 2015;29(6):1603-1610.

15. Swann JW, Skelly BJ. Systematic review of prognostic factors for mortality in dogs with immune-mediated hemolytic anemia. $J$ Vet Intern Med. 2015;29(1):7-13.

16. Whelan M, Rozanski E, O'Toole T, Crawford S, Holm J, Cotter S. Use of the canine haemolytic anaemia objective score (CHAOS) to predict survival in dogs with immune mediated haemolytic anaemia. JVet Intern Med. 2006;20:714-715. [Abstract].

17. Ishihara M, Fujino Y, Setoguchi A, et al. Evaluation of prognostic factors and establishment of a prognostic scoring system for canine primary immune-mediated hemolytic anemia. J Vet Med Sci. 2010;72(4):465-470.

18. Ke SS, Anderson GA, Connolly SL. Evaluation of prognostic indicators for canine primary immune-mediated haemolytic anaemia and application of a scoring system for the determination of prognosis. Aust Vet J. 2015;93(4):93-98.

19. Duval D, Giger U. Vaccine-associated immune-mediated hemolytic anemia in the dog. J Vet Intern Med. 1996;10(5):290-295.

20. McAlees TJ. Immune-mediated haemolytic anaemia in 110 dogs in Victoria, Australia. Aust Vet J. 2010;88(1-2):25-28.

21. Holahan ML, Brown AJ, Drobatz KJ. The association of blood lactate concentration with outcome in dogs with idiopathic immune-mediated hemolytic anemia: 173 cases (2003-2006). J Vet Emerg Crit Care. 2010;20(4):413-420.

22. Carr AP, Panciera DL, Kidd L. Prognostic factors for mortality and thromboembolism in canine immune-mediated hemolytic anemia: a retrospective study of 72 dogs. J Vet Intern Med. 2002;16(5):504-509.

23. Whelan MF, O'Toole TE, Chan DL, et al. Use of human immunoglobulin in addition to glucocorticoids for the initial treatment of dogs with immune-mediated hemolytic anemia. J Vet Emerg Crit Care. 2009;19(2):158-164.

24. Reimer M, Troy G, Warnick L. Immune-mediated hemolytic anemia: 70 cases (1988-1996). J Am Anim Hosp Assoc. 1999;35(5):384-391. 
25. Rozanski E, Callan M, Hughes D, Sanders N, Giger U. Comparison of platelet count recovery with the use of vincristine and prednisolone or prednisolone alone for treatment of severe immune mediated thrombocytopenia in dogs. J Am Vet Med Assoc. 2002;220(4):477-481.

26. Barcellini W. Current treatment strategies in autoimmune hemolytic disorders. Expert Rev Haematol. 2015;8(5):681-691.

27. Massari F, Mastropasqua F, Iacovielli M, Nuzzolese V, Torres D, Parinello G. The glucocorticoid in acute decompensated heart failure: Dr Jekyll or Mr Hyde? Am J Emerg Med. 2012;30(3): 517.e5-517.e10.

28. Wallisch K, Trepanier LA. Incidence, timing, and risk factors of azathioprine hepatotoxicosis in dogs. J Vet Intern Med. 2015;29(2):513-518.

29. Namikawa K, Maruo T, Honda M, Hirata H, Lynch J, Madarame H. Gingival overgrowth in a dog that received long-term cyclosporine for immune-mediated hemolytic anemia. Can Vet J. 2012; 53(1):67-70

30. Dowling SR, Webb J, Foster JD, Ginn J, Foy DS, Trepanier LA. Opportunistic fungal infections in dogs treated with ciclosporin and glucocorticoids: eight cases. J Small Anim Pract. Epub 2015 May 18.

31. Trehy, M., Whitley N, Battersby I [homepage on the Internet]. The Use of Lithium Carbonate in the Treatment of Pure Red Cell Aplasia in Dogs: 5 Cases (2006-2010). British Small Animal Veterinary Congress; 2011. Available from: http://www.vin.com/. Accessed April 20, 2016.

32. Sontas H, Dokuzeylu B, Turna O, Ekici H. Estrogen-induced myelotoxicity in dogs: a review. Can Vet J. 2009;50(10):1054-1058.

33. Crump KL, Seshadri R. Use of therapeutic plasmapheresis in a case of canine immune- mediated hemolytic anemia. JVet Emerg Crit Care (San Antonio). 2009;19(4):375-380.

34. Peterson AL, Torres SM, Rendahl A, Koch SN. Frequency of urinary tract infection in dogs with inflammatory skin disorders treated with ciclosporin alone or in combination with glucocorticoid therapy: a retrospective study. Vet Dermatol. 2012;23(3):201-e43.

35. MacNeill AL, Steeil JC, Dossin O, Hoien-Dalen PS, Maddox CW. Disseminated nocardiosis caused by Nocardia abscessus in a dog. Vet Clin Pathol. 2010;39(3):381-385.

36. Paul AE, Mansfield CS, Thompson M. Presumptive Nocardia spp. infection in a dog treated with cyclosporin and ketoconazole. $N \mathrm{Z} \mathrm{Vet}$ J. 2010;58(5):265-268.

37. Siak MK, Burrows AK. Cutaneous nocardiosis in two dogs receiving ciclosporin therapy for the management of canine atopic dermatitis. Vet Dermatol. 2013;24(453-456):453-e103.

38. Callan MB, Preziosi D, Mauldin E. Multiple papillomavirus-associated epidermal hamartomas and squamous cell carcinomas in situ in a dog following chronic treatment with prednisone and cyclosporine. Vet Dermatol. 2005;16(5):338-345.

39. Kronbichler A, Jayne DR, Mayer G. Frequency, risk factors and prophylaxis of infection in ANCA-associated vasculitis. Eur J Clin Invest. 2015;45(3):346-368.

40. Pawelec K, Salamonowicz M, Panasiuk A, Matysiak M, Demkow U. Respiratory and systemic infections in children with severe aplastic anemia on immunosuppressive therapy. Adv Exp Med Biol. 2013;788:417-425.

41. Watson PJ, Wotton P, Eastwood J, Swift ST, Jones B, Day MJ. Immunoglobulin deficiency in Cavalier King Charles Spaniels with Pneumocystis pneumonia. J Vet Intern Med. 2006;20(3):523-527.

42. Kanemoto H, Morikawa R, Chambers JK, et al. Common variable immune deficiency in a Pomeranian with Pneumocystis carinii pneumonia. J Vet Med Sci. 2015;77(6):715-719.

43. Lobetti R. Common variable immunodeficiency in miniature dachshunds affected with Pneumonocystis carinii pneumonia. J Vet Diagn Invest. 2000;12(1):39-45.

44. Hoon-Hanks LL, Regan D, Dubey JP, Carol Porter M, Duncan CG. Hepatic neosporosis in a dog treated for pemphigus foliaceus. $J$ Vet Diagn Invest. 2013;25(6):807-810.

45. Galgut BI, Janardhan KS, Grondin TM, Harkin KR, Wight-Carter MT. Detection of Neospora caninum tachyzoites in cerebrospinal fluid of a dog following prednisone and cyclosporine therapy. Vet Clin Pathol. 2010;39(3):386-390.
46. Bernsteen L, Gregory CR, Aronson LR, Lirtzman RA, Brummer DG. Acute toxoplasmosis following renal transplantation in three cats and a dog. J Am Vet Med Assoc. 1999;215(8):1123-1126.

47. Burgess K, Moore A, Rand W, Cotter S. Treatment of immunemediated hemolytic anemia with cyclophosphamide. JVet Intern Med. 2000;14(4):456-462.

48. Kellerman D, Bruyette D. Intravenous human immunoglobulin for the treatment of immune-mediated hemolytic anemia in 13 dogs. JVet Intern Med. 1997;11(6):327-332.

49. Scott-Moncrieff C, Reagan W, Glickman L, Denicola D, Harrington D. Treatment of non-regenerative anemia with human gammaglobulin in dogs. J Am Vet Med Assoc. 1995;206(12):1895-1900.

50. Scott-Moncrieff C, Reagan W, Snyder P, Glickman L. Intravenous administration of human immune globulin in dogs with immune-mediated hemolytic anemia. J Am Vet Med Assoc. 1997;210(11):1623-1627.

51. Grundy $S$, Barton C. Influence of drug treatment on survival of dogs with immune- mediated hemolytic anemia: 88 cases (1989-1999). J Am Vet Med Assoc. 2001;218(4):543-546.

52. Akpek G, McAneny D, Weintraub L. Comparative response to splenectomy in Coombs-positive autoimmune hemolytic anemia with or without associated disease. Am J Haematol. 1999;61(2):98-102.

53. Feldman B, Handagama P, Lubberink A. Splenectomy as adjunctive therapy for immune-mediated thrombocytopenia and hemolytic anemia in the dog. J Am Vet Med Assoc. 1985;187(6):617-619.

54. Horgan J, Roberts B, Schermerhorn T. Splenectomy as an adjunctive treatment for dogs with immune-mediated hemolytic anemia: ten cases (2003-2006). J Vet Emerg Crit Care. 2009;19(3):254-261.

55. Piek C, van Spil W, Junius G, Dekker A. Lack of evidence of a beneficial effect of azathioprine in dogs treated with prednisolone for idiopathic immune-mediated hemolytic anemia: a retrospective cohort study. $B M C$ Vet Res. 2011;7:15-23.

56. Stokol T, Blue JT, French TW. Idiopathic pure red cell aplasia and non-regenerative anemia in dogs: 43 cases (1988-1999). J Am Vet Med Assoc. 2000;216(9):1429-1436.

57. Abkowitz J, Kadin M, Powell J, Adamson J. Pure red cell aplasia: lymphocyte inhibition of erythropoesis. Br J Haematol. 1986;63(1):59-67.

58. Weiss D. Antibody-mediated suppression of erythropoesis in dogs with red blood cell aplasia. Am J Vet Res. 1986;47(12):2646-2648.

59. Weiss D. Bone marrow pathology in dogs and cats with non-regenerative immune-mediated haemolytic anaemia and pure red cell aplasia. J Comp Pathol. 2008;138(1):46-53.

60. Weinkle TK, Center SA, Randolph JF, Warner KL, Barr SC, Erb HN. Evaluation of prognostic factors, survival rates, and treatment protocols for immune-mediated hemolytic anemia in dogs: 151 cases (1993-2002). J Am Vet Med Assoc. 2005;226(11):1869-1880.

61. Kidd L, Mackman N. Prothrombotic mechanisms and anticoagulant therapy in dogs with immune-mediated hemolytic anemia. JVet Emerg Crit Care. 2013;23(1):3-13.

62. Scott-Moncrieff JC, Treadwell NG, McCullough SM, Brooks MB. Hemostatic abnormalities in dogs with primary immune-mediated hemolytic anemia. J Am Anim Hosp Assoc. 2001;37(3):220-227.

63. Fluckiger MA, Gomez JA. Radiographic findings in dogs with spontaneous pulmonary thrombosis or embolism. Vet Radiol. 1984;25(3):124-131.

64. Johnson LR, Lappin MR, Baker DC. Pulmonary thromboembolism in 29 dogs: 1985-1995. J Vet Intern Med. 1999;13(4):338-345.

65. Goggs R, Chan DL, Benigni L, Hirst C, Kellett-Gregory L, Fuentes VL. Comparison of computed tomography pulmonary angiography and point-of-care tests for pulmonary thromboembolism diagnosis in dogs. J Small Anim Pract. 2014;55(4):190-197.

66. Goggs R, Benigni L, Fuentes VL, Chan DL. Pulmonary thromboembolism. J Vet Emerg Crit Care. 2009;19(1):30-52.

67. Sinnott VB, Otto CM. Use of thromboelastography in dogs with immune-mediated hemolytic anemia: 39 cases (2000-2008). JVet Emerg Crit Care. 2009;19(5):484-488.

68. Goggs R, Wiinberg B, Kjelgaard-Hansen M, Chan D. Serial assessment of the coagulation status of dogs with immune-mediated haemolytic anaemia using thromboelastography. Vet J. 2012;191(3):347-353. 
69. Mellett AM, Fenimore AC, Nakamura RK, Bianco D. Prospective evaluation of clopidogrel, ultra-low-dose aspirin, or both in dogs with primary immune-mediated hemolytic anemia. J Vet Int Med. 2010;24:755.

70. Streiff MB, Agnelli G, Connors JM, et al. Guidance for the treatment of deep vein thrombosis and pulmonary embolism. JThromb Thrombolysis. 2016;41(1):32-67.

71. Helmond S, Polzin D, Armstrong P, Finke M, Smith S. Treatment of immune-mediated hemolytic anemia with individually adjusted heparin dosing in dogs. J Vet Intern Med. 2010;24(3):597-605.

72. Hylek EM, Regan S, Henault LE, et al. Challenges to the effective use of unfractionated heparin in the hospitalized management of acute thrombosis. Arch Intern Med. 2003;163(5):621-627.

73. Sangster CR, Stevenson CK, Kidney BA, Montgomery DL, Allen AL. Kernicterus in an adult dog. Vet Pathol. 2007;44(3):383-385.

74. Belz KM, Specht AJ, Johnson VS, Conway JA. MRI findings in a dog with kernicterus. J Am Anim Hosp Assoc. 2013;49(4):286-292.

75. Shearer LR, Boudreau AE, Holowaychuk MK. Distal renal tubular acidosis and immune-mediated hemolytic anemia in 3 dogs. J Vet Int Med. 2009;23(6):1284-1288.

76. Caruana RJ, Buckalew VM. The syndrome of distal (type-1) renal tubular-acidosis - clinical and laboratory findings in 58 cases. Medicine. 1988;67(2):84-99.

77. Pessler F, Emery H, Dai L, et al. The spectrum of renal tubular acidosis in paediatric Sjogren syndrome. Rheumatology. 2006;45(1):85-91.

78. Ter Meulen CG, Pieters GFFM, Huysmans FTM. Flaccid paresis due to distal renal tubular acidosis preceding systemic lupus erythematosus. Neth J Med. 2002;60(1):29-32.

79. Bossini N, Savoldi S, Franceschini F, et al. Clinical and morphological features of kidney involvement in primary Sjogren's syndrome. Nephrol Dial Transplant. 2001;16(12):2328-2336.
80. Bae EH, Han CW, Lee JH, et al. The Case. Hypokalemia associated with nephrocalcinosis. Distal renal tubular acidosis associated with Sjögren's syndrome. Kidney Int. 2009;75(4):443-444.

81. Both T, Zietse R, Hoorn EJ, et al. Everything you need to know about distal renal tubular acidosis in autoimmune disease. Rheumatol Int. 2014;34(8):1037-1045.

82. Harrison HE, Bunting H, Ordway NK, Albrink WS. The pathogenesis of the renal injury produced in the dog by hemoglobin or methemoglobin. J Exp Med. 1947;86(4):339-356.

83. Deuel JW, Schaer CA, Boretti FS, et al. Hemoglobinuria-related acute kidney injury is driven by intrarenal oxidative reactions triggering a heme toxicity response. Cell Death Dis. 2016;7:e2064.

84. Lobetti R. Changes in the serum urea: creatinine ratio in dogs with babesiosis, haemolytic anaemia, and experimental haemoglobinaemia. Vet J. 2012;191(2):253-256.

85. Lobetti RG, Reyers F, Nesbit JW. The comparative role of haemoglobinaemia and hypoxia in the development of canine babesial nephropathy. J S Afr Vet Assoc. 1996;67(4):188-198.

86. Rinaldi M, Perricone C, Ortega-Hernandez OD, Perricone R, Shoenfeld Y. Immune thrombocytopaenic purpura: an autoimmune cross-link between infections and vaccines. Lupus. 2014;23(6):554-567.

87. Seltsam A, Shukry-Schulz S, Salama A. Vaccination-associated immune hemolytic anemia in two children. Transfusion. 2000;40(8):907-909.

88. Schuller S, Francey T, Hartmann K, et al. European consensus statement on leptospirosis in dogs and cats. J Small Anim Pract. 2015;56(3): 159-179.

89. Salama A. Treatment options for primary autoimmune hemolytic anemia: a short comprehensive review. Transfus Med Hemother. 2015;42(5):294-301.

90. Miano M. How I manage Evans Syndrome and AIHA cases in children. Br J Haematol. 2015;172(4):524-534.
Veterinary Medicine: Research and Reports

\section{Publish your work in this journal}

Veterinary Medicine: Research and Reports is an international, peer-reviewed, open access journal publishing original research, case reports, editorials, reviews and commentaries on all areas of veterinary medicine. The manuscript management system is completely online and includes a very quick and fair peer-review system.

\section{Dovepress}

Visit http://www.dovepress.com/testimonials.php to read real quotes from published authors. 